\title{
Bacteriological Profile of Pneumopathies in Chronic Renal Failure at the University Hospital Center of Point-G in Mali
}

\author{
Seydou Sy ${ }^{1,2 *}$, Magara Samaké2,3, Hamadoun Yattara ${ }^{1,2}$, Moctar Coulibaly4, Ba Oumou Diallo1, \\ Aboubacar Sidiki Fofana1, Djénéba Diallo1,2, Atabieme Kodio1, Modi Sidibé1, \\ Nouhoum Coulibaly', Alkaya Touré1, Djibril Sy ${ }^{2,5}$, Moustapha Tangara ${ }^{1,2}$, Saharé Fongoro ${ }^{1,2}$ \\ ${ }^{1}$ Nephrology and Haemodialysis Department of the University Hospital Center (CHU) of Point G, Bamako, Mali \\ ${ }^{2}$ Faculty of Medicine of Bamako, University of Bamako, Bamako, Mali \\ ${ }^{3}$ Nephrology Unit of the Fousseyni DAOU Hospital of Kayes, Kayes, Mali \\ ${ }^{4}$ Nephrology Unit of Mali GAVARDO Hospital, Bamako, Mali \\ ${ }^{5}$ Internal Medicine Service of the University Hospital Center of Point G (CHU du Point-G), Bamako, Mali \\ Email: *seydousy2002@yahoo.fr
}

How to cite this paper: Sy, S., Samaké, M., Yattara, H., Coulibaly, M., Diallo, B.O., Fofana, A.S., Diallo, D., Kodio, A., Sidibé, M., Coulibaly, N., Touré, A., Sy, D., Tangara, M. and Fongoro, S. (2020) Bacteriological Profile of Pneumopathies in Chronic Renal Failure at the University Hospital Center of Point-G in Mali. Open Journal of Clinical Diagnostics, 10, 18-28. https://doi.org/10.4236/ojcd.2020.101002

Received: December 24, 2019

Accepted: February 11, 2020

Published: February 14, 2020

Copyright $\odot 2020$ by author(s) and Scientific Research Publishing Inc. This work is licensed under the Creative Commons Attribution International License (CC BY 4.0).

http://creativecommons.org/licenses/by/4.0/ (c) (i) Open Access

\begin{abstract}
Introduction: Chronic renal failure $(\mathrm{CKD})$ is defined as a glomerular filtration rate (GFR) of less than $60 \mathrm{ml} / \mathrm{min} / 1.73 \mathrm{~m}^{2}$ for more than 3 months [1]. Infectious complications are a major source of morbidity in patients with chronic renal failure. In Mali, we have no data on pneumopathies in this population, hence the interest of this study. The objective of this work was to determine the frequency of pneumopathies in patients with chronic renal failure, describe the clinical radio-types, identify the microorganisms involved, and assess the renal prognosis of pneumopathies. Materials and Methods: This was an 18-month prospective and descriptive study from January 1, 2018 to June 30, 2019 conducted in the nephrology and hemodialysis department of the University Hospital of Point G. Included were patients hospitalized during our study period with CKD associated with pneumopathy on a chest X-ray. Not included were all patients hospitalized outside the study period, all CKD cases without pneumonia, patients with incomplete records, and non-consenting patients. Results: We examined 1111 patients, 35 of whom presented an image on chest X-ray related to pneumopathy, a frequency of $3.15 \%$ of cases. Twenty-one men $(60 \%)$ and 14 women $(40 \%)$ with a sex ratio of 1.5. The mean age was $46.8 \pm 13.9$ years with extremes of 23 and 76 years. The types of pneumopathy on the chest X-ray were: alveolar pneumopathy: 23 cases $(65.7 \%)$, pleuropneumopathy: 10 cases $(28.6 \%)$ and cavitary pneumopathy: 2 cases (5.7\%). Cytobacteriological sputum examination was positive in $65.7 \%$; leukocytes (68.6\% of cases). The germs found were: Klebsiella
\end{abstract}


pneumoniae (25.7\% of cases), Escherica coli (11.4\%), Pseudomonas aeruginosa (5.7\%), Staphylococcus aureus (5.7\%), Citrobacter freundi (5.7\%), Enterococus sp. (2.9\%), Enterobacter cloacae (2.9\%), Candida albicans (5.7\%). The search for acid-alcohol-resistant bacilli (BAAR) in sputum was positive in 4 cases (11.4\%). There was an association between the results of cytobacteriological examination of sputum and the results of BAAR testing of sputum ( $\mathrm{p}$ $=0.046)$.

\section{Keywords}

Renal Failure, Dialysis, Pneumopathy, Mali

\section{Introduction}

Chronic renal failure (CKD) is defined as a glomerular filtration rate (GFR) of less than $60 \mathrm{ml} / \mathrm{min} / 1.73 \mathrm{~m}^{2}$ for more than 3 months [1].

Infectious complications are a major source of morbidity in patients with chronic renal failure [2]. In a prospective study on a cohort of 1455 patients with chronic renal failure in France, the frequency of infectious episodes was 39 per 100 patient-years [3] [4]. In the same study, the frequency of pneumopathies was about 13 episodes per 100 patient-years, compared to only 1.5 episodes per 1000 subjects per year in France in the general population. In the HEMO study conducted in the United States on a cohort of 1846 hemodialysis patients, $42.4 \mathrm{p}$. 100 of the patients were hospitalized at least once in 34 months for a serious infection, and the incidence of pneumonia was $21 \%$ [5].

Pneumopathies are a frequent, serious and often difficult to diagnose etiologically in patients with chronic renal failure. Because of their frequency, severity and specific links with reduced immune defences, pneumopathies of infectious origin are the first cause to be mentioned. However, non-infectious etiologies can be a difficult differential diagnosis [6]. The identification of the microorganisms in question requires urgent further exploration. The urgency of antiinfectious treatment generally requires presumptive treatment oriented according to the immune deficiency involved and the etiological suspicion. The objective of this work was to determine the frequency of pneumopathies in patients with chronic renal failure, to describe the radio-clinical lesions, to identify the microorganisms involved and to evaluate the renal prognosis of the pneumopathies.

\section{Materials and Methods}

This was an 18-month prospective and descriptive study from January 1, 2018 to June 30, 2019 conducted in the nephrology and hemodialysis department of the G-spot University Hospital. It covered patients hospitalized for chronic renal failure, whether or not they were on hemodialysis, who presented with pneumopathy during that period, regardless of sex, age and nationality. Not included 
in the study were all patients hospitalized outside the study period, all cases of chronic renal failure without pneumopathy, patients with incomplete records, and non-consenting patients.

The material consisted of the hospitalization register, hospitalization records, an individual survey form with sociodemographic data, clinical summaries, results of additional examinations, management and surveillance measures.

Chronic renal failure is defined as a progressive and irreversible decrease in GFR below $60 \mathrm{ml} / \mathrm{min} / 1.73 \mathrm{~m}^{2}$ for at least 3 months, whether or not associated with other markers of renal impairment (proteinuria, hematuria, morphological or histological abnormalities).

Pneumopathy is an infection of the respiratory system and lungs.

There are several types of pneumopathy:

Alveolar pneumopathy: Alveolar syndrome consists of opacities characterized by one or more of the following radiological criteria:

- systematicized lobar or segmental distribution;

- blurred boundaries;

- tendency to confluence;

- broncho gram and/or aerial alveologram;

- divided into butterfly wings.

Interstitial lung disease: This is defined as the set of radiological signs indicating an injury to the interstitial area of the lung. The pulmonary interstitium is the connective tissue supporting the lung. It is divided into three sectors, the peripheral sector, the axial sector and the alveolar walls. Involvement of the peripheral area results in subpleural edema and Kerley lines A or B. Involvement of the peribronchovascular axial area results in peribronchovascular hilifugal opacities and erasure of vascular contours in the hilar and para-hilar regions.

Nodular Pneumopathy: Characterized by micronodular opacities or miliary images. These opacities are round, 1 to $3 \mathrm{~mm}$ in diameter, generally uniform in size and with relatively sharp contours.

Bronchial pneumopathy: This is a symptom of parietal thickening, dilation of the lumen and abnormal accumulation of secretions in the bronchial tubes.

Parietal thickening is characterized by ring-shaped images with more or less thick walls and parallel linear opacities drawing tube-shaped clefts.

Cavity or excavated lung disease: This is defined by the presence of one or more cavities in the lung. A lung cavity is a circumscribed parenchymal hyperclearness, i.e. surrounded by a wall of variable thickness. Excavation or cavitation is the appearance of a cavity

Sociodemographic (age, sex, occupation, ethnicity, provenance), clinical (interview and physical examination), biological and radiological data were collected from all patients. These data were collected through a comprehensive clinical examination and additional biological and radiological examinations.

The parameters studied were:

- In the blood: $\mathrm{CBC}$, blood ionogram, serum calcium, serum phosphorus, se- 
rum creatinine, $\mathrm{C}$-reactive protein (CRP) and procalcitonin.

- In the urine: The cyto-bacteriological examination of urine (ECBU) in search of a urinary infection (leukocytes $\geq 10,000 / \mathrm{ml}$ ) with or without hematuria $\geq$ $10,000 / \mathrm{ml}$, a bacteriuria $\geq 100,000 \mathrm{ml}$ ).

- In the sputum: The sputum cytobacteriological examination (ECBC) will look for leukocytes $\geq 10 \mathrm{~mm}^{3}$, red blood cells $\geq 10 \mathrm{~mm}^{3}$, the presence or not of the germ $\left(10^{5} / \mathrm{mm}^{3}\right)$. The search for acid-alcohol-resistant bacilli (BAAR) will confirm the presence of BK (Bacille of Koch).

- Medical Imaging: X-ray of the front chest to look for pneumopathy, whether alveolar, interstitial, bronchial or other, and assess the cardiac condition.

Verbal informed consent was obtained from patients after explanation of the purpose of the study. In order to ensure the confidentiality of the results, the anonymity of medical records was strictly respected.

Data processing was performed on Microsoft office 2017 software, data entry and analysis on the SPSS20. The statistical test used was Chi-square with $\mathrm{P}<$ 0.05 significance value.

\section{Results}

We examined 1111 patients, 35 of whom presented an image on chest X-ray related to pneumopathy, a frequency of $3.15 \%$ of cases.

Twenty-one men (60\%) and 14 women (40\%) with a sex ratio of 1.5 . The mean age was $46.8 \pm 13.9$ years with extremes of 23 and 76 years.

The medical history of our patients were: hypertension: 26 cases $(74.3 \%)$, diabetes: 4 cases (11.4\%), HIV: 3 cases (8.6\%), tuberculosis: 3 cases (8.6\%), hypertension plus diabetes: 2 cases $(5.7 \%)$, sickle cell disease: 1 case $(2.9 \%)$ and malaria: 1 case $(2.9 \%)$.

The functional signs were: cough (100\%), dyspnea (94.3\%). The physical signs were: crackling rales (88.6\%), suppression of vesicular murmur (17.1\%), sibilants (5.7\%), fever in $57.1 \%$ of cases (Cf. Table 1 and Table 2).

The types of pneumopathy on the chest X-ray were: alveolar pneumopathy: 23 cases (65.7\%), pleuropneumopathy: 10 cases (28.6\%) and cavitary pneumopathy: 2 cases (5.7\%) (Cf. Table 3 and Figures 1-3).

Cytobacteriological examination of sputum was positive in $65.7 \%$; leukocytes (68.6\% of cases). The germs found were: Klebsiella pneumoniae (25.7\% of cases), Escherica. coli (11.4\%), Pseudomonas aeruginosa (5.7\%), Staphylococcus aureus (5.7\%), Citrobacter freundi (5.7\%), Enterococus sp. (2.9\%), Enterobacter cloacae (2.9\%), Candida albicans (5.7\%) (Cf. Table 4).

The search for acid-alcohol-resistant bacilli (BAAR) in sputum was positive in 04 cases $(11.4 \%)$. There was a statistically significant relationship between the results of cytobacteriological examination of sputum and the results of finding ASPB in sputum ( $\mathrm{p}=0.046)$ (See Table 5).

Infectious and/or inflammatory parameters: increased CRP (100\%), hyperleukocytosis (60\%), leukopenia (5.7\%), increased procalcitonin (65.7\%). 
The molecules tested and sensitive were Ceftazidim (37.1\%), Ciprofloxacin (22.9\%), Amoxicillin-clavulanic acid (17.1\%), Gentamicin (17.1\%), Meronia (11.4\%), Zaxter (8.6\%) and Erythromicin (2.9\%).

There was a urinary co-infection in $40 \%$ of cases. The germs isolated in uroculture were E. coli (17.1\%), S. aureus (5.7\%), Enterococcus sp. (5.7\%),

Table 1. Distribution of patients according to functional signs.

\begin{tabular}{|c|c|c|}
\hline Functional signs & Staff & Percentage \\
\hline Cough & 35 & 100 \\
\hline Dyspnea & 33 & 94.3 \\
\hline Vomiting & 33 & 94.3 \\
\hline Physical Asthenia & 31 & 88.6 \\
\hline Epigastralgia & 30 & 85.7 \\
\hline Anorexia & 29 & 82.9 \\
\hline Signs of arterial hypertension & 27 & 77.1 \\
\hline Muscle cramps & 27 & 77.1 \\
\hline Insomnia & 26 & 74.3 \\
\hline Other functional signs ${ }^{*}$ & 11 & 31.4 \\
\hline Edematous syndromes & 20 & 57.1 \\
\hline Constipation & 12 & 34.3 \\
\hline Epistaxis & 11 & 31.4 \\
\hline Anorexia & 4 & 11.4 \\
\hline Diarrhoea & 4 & 11.4 \\
\hline Haematodesis & 4 & 11.4 \\
\hline Lumbar pain & 4 & 11.4 \\
\hline
\end{tabular}

One hundred percent $(100 \%)$ of the patients had a cough. ${ }^{*}$ Other functional signs: convulsion (2), rectorragie (2), uremic breath (3), orthopnea (1), tremulation (3).

Table 2. Distribution by pulmonary signs.

\begin{tabular}{ccc}
\hline Lung signs & Staff & Percentage \\
\hline Crackling rales & 31 & 88.6 \\
Abolition of vesicular murmurs & 6 & 17.1 \\
Sibilants & 2 & 5.7 \\
\hline
\end{tabular}

Thirty-one patients had crackling rales.

Table 3. Distribution by type of pneumopathy on chest $\mathrm{x}$-ray of the frontal chest.

\begin{tabular}{ccc}
\hline Result on the frontal X-ray & Staff & Percentage \\
\hline Alveolar pneumopathy & 23 & 65.7 \\
Pleuropneumopathy & 10 & 28.6 \\
Cavitary lung disease & 2 & 5.7 \\
\hline
\end{tabular}

Alveolar pneumopathy was found in $65.7 \%$ of cases. 


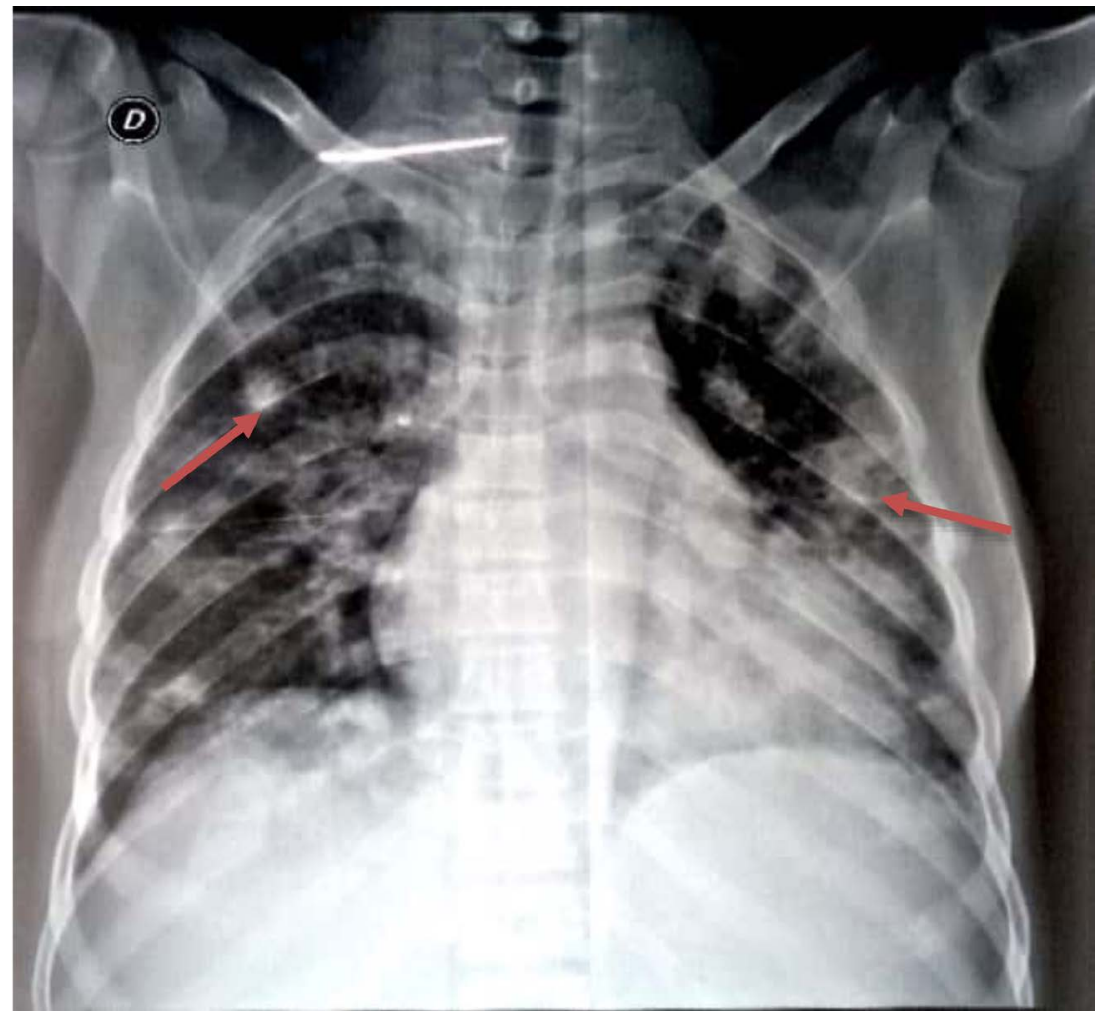

Figure 1. X-ray of the frontal thorax showing multiple diffuse alveolar opacities in the 2 pulmonary fields with blurred contours and aerial bronchograms.

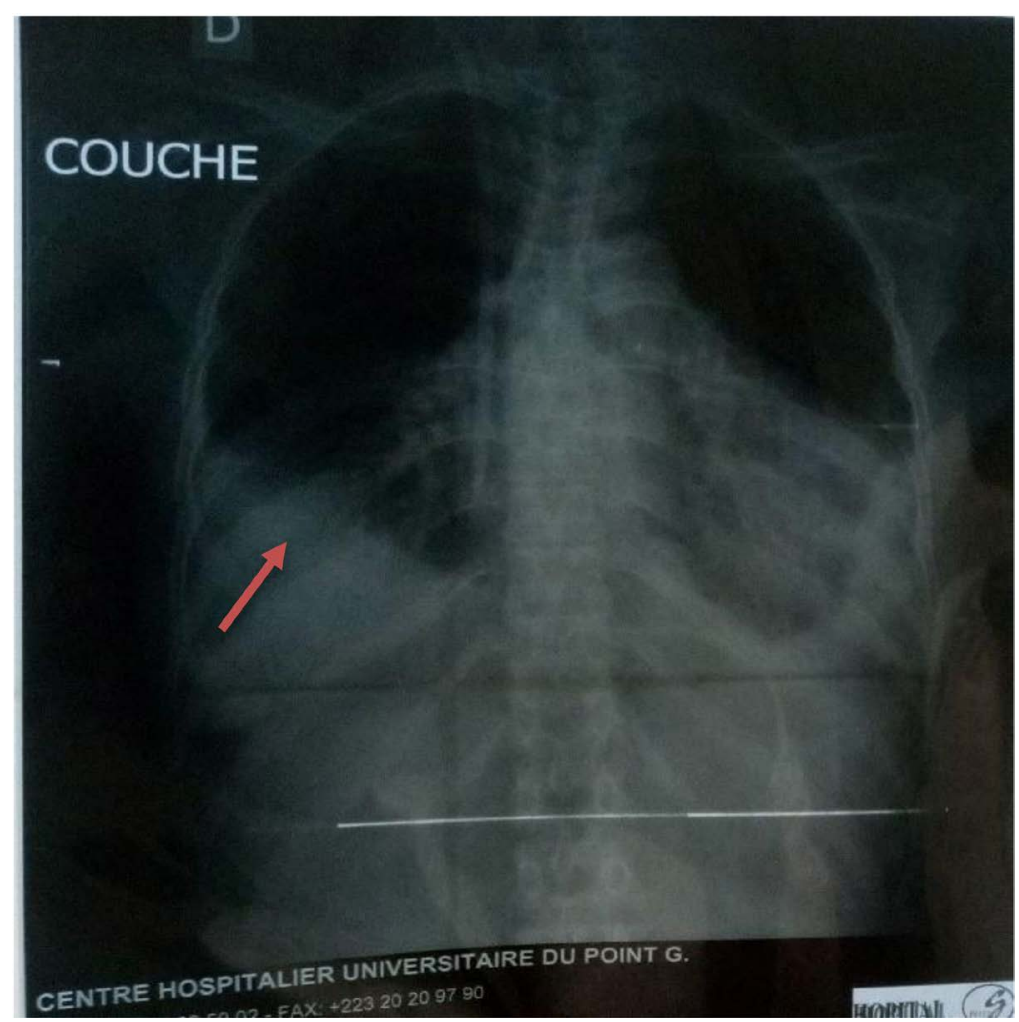

Figure 2. Frontal chest X-ray objectivizing bilateral pleurisy with alveolar opacities of the right lung (Pleuropneumopathy). 


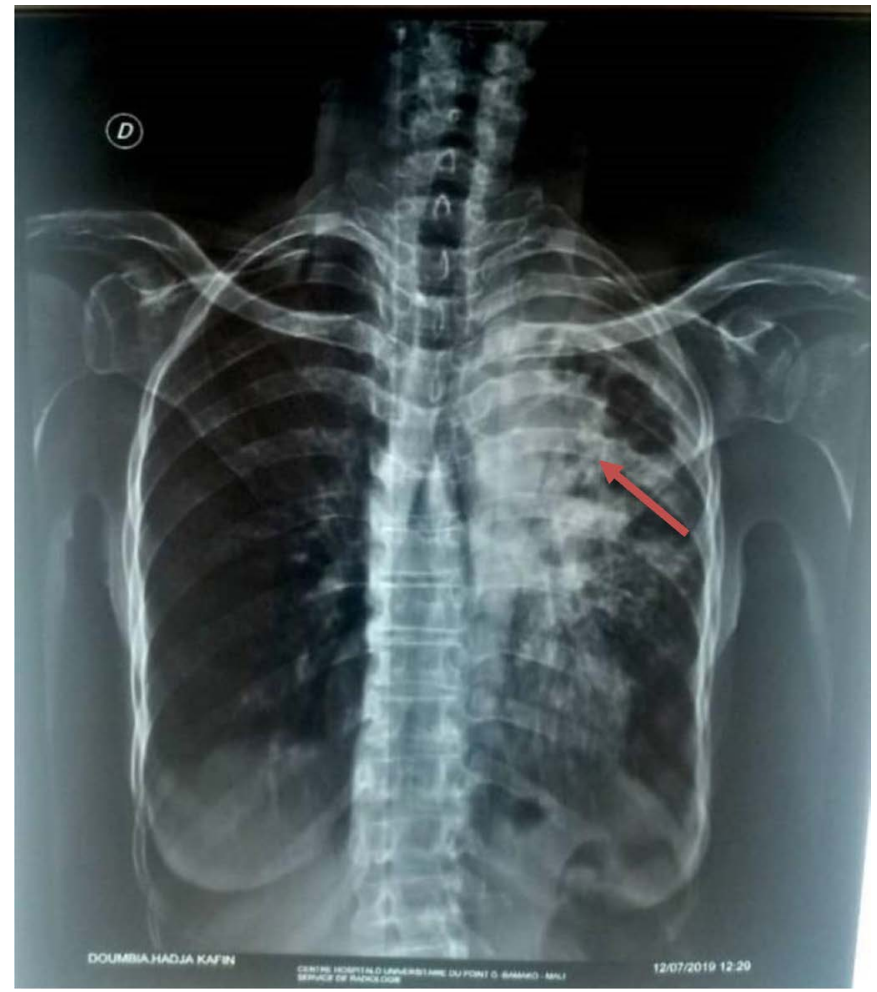

Figure 3. Frontal thoracic radiograph showing a heterogeneous opacity of the left upper lobe associated with a voluminous left apical excavated opacity: aspect of a cavitary pleuro-pneumopathy.

Table 4. Spit-up distribution by germ isolated at ECBC.

\begin{tabular}{ccc}
\hline Germs & Staff & Percentage \\
\hline Klebsiella pneumoniae & 9 & 25.7 \\
Esherichia coli & 4 & 11.4 \\
Candida albicans & 2 & 5.7 \\
Pseudomonas aeroginosa & 2 & 5.7 \\
Staphylococcus aureus & 2 & 5.7 \\
Citrobacter freundii & 2 & 5.7 \\
Enterococus sp. & 1 & 2.9 \\
Enterobacter claocae & 1 & 2.9 \\
Sterile & 12 & 34.3 \\
\hline
\end{tabular}

Klebsiella pneumoniae was isolated in $25.7 \%$ of cases.

Table 5. Breakdown by outcome of BAAR search in sputum.

\begin{tabular}{ccc}
\hline BAAR search in spit & Staff & Percentage \\
\hline Negative & 31 & 88.6 \\
Positive & 4 & 11.4 \\
Total & 35 & 100 \\
\hline
\end{tabular}

Pulmonary tuberculosis was diagnosed in 4 cases or $11.4 \%$ of patients. 
Acinetobacter baumani (2.9\%), Klebsiella pneumoniae (2.9\%), Pseudomonas aeruginosa (2.9\%), Candida albicans (2.9\%). There was no statistically significant relationship between germs found on cytobacteriological examination of sputum and cytobacteriological examination of urine $(\mathrm{p}=0.576)$.

The main etiologies of chronic renal failure in our study were hypertensive (37.2\%), glomerular (20\%), tubulo-interstitial (14.3\%), ischemic (11.4\%), diabetic $(8.6 \%)$ and of undetermined cause $(8.6 \%)$ of cases.

The evolution under treatment of pneumopathy was favourable in $74.3 \%$ with sputum sterilization (28.6\%), normalization of CRP and procalcitonin in $48.8 \%$ and $31.4 \%$ respectively. The control chest X-ray was normal in $37.1 \%$ of cases. On the renal level, the evolution under treatment of pneumopathy was marked by the regression of the stigma of renal damage (creatininemia and blood urea) in $57.1 \%$ of cases, stabilization of renal function in $14.3 \%$ and 9 cases of death.

\section{Discussion}

Limitations of the study: patients whose records were incomplete due to lack of financial means to carry out radiological and biological explorations, their return home against medical advice, non-consent and the occurrence of death contributed to reducing our workforce.

During the study period, there were 1111 patients who were diagnosed with CKD. Among them 35 patients presented an image of pneumopathy on a chest $\mathrm{X}$-ray of the face, i.e. $3.15 \%$. This frequency in Togo and Algeria was $5.4 \%$ and $12.2 \%$ respectively in 2017 [7] [8]. In a study in France, the frequency of pneumonia was about 13 episodes per 100 patient-years, compared to only 1.5 episodes per 1000 subjects per year in the general population [3] [4]. The incidence of bacterial pneumopathy was $34 \%$ in the study by Rieu $\mathrm{Ph}$ [9]. In the HEMO study conducted in the United States on a cohort of 1846 hemodialysis patients, $42.4 \%$ of the patients were hospitalized at least once in 34 months for a serious infection, and the incidence of pneumonia was $21 \%$ [5].

The sample consisted of 21 men (60\%) and 14 women (40\%), with a sex ratio of 1.5. Studies in Togo and Morocco reported male dominance in $60 \%$ and $59.1 \%$ of cases respectively [7] [9]. The mean age was $46.8 \pm 13.9$ years with extremes of 23 and 76 years. Maiga in Togo reported an average age of $51.87 \pm 16.7$ years [7].

All patients were given a complete clinical examination, particularly pleuro-pulmonary. The functional signs found were, in order of increasing frequency: productive cough (100\%), dyspnea (94.3\%). Physical examination revealed crackling rales $(88.6 \%)$, suppression of vesicular murmurs $(17.1 \%)$, sibilant rales (5.7\%), fever (57.1\%). These results are similar to those of Ouldittou in Morocco, which reported cough with sputum in all cases with crackling rales (70\%), suppression of vesicular murmurs (30\%) and fever in $84 \%$ of cases [9].

The types of pneumopathy on the chest $\mathrm{x}$-ray were: alveolar pneumopathy (65.7\%), pleuropneumopathy (28.6\%) and cavitary pneumopathy (5.7\%). Oul- 
dittou in Morocco had alveolar-type opacity in all cases on facial radiography: unilateral in $76 \%$ of cases and bilateral in $24 \%$ of cases. Bacterial pneumopathies were common in elderly subjects with an age range of 56 - 65 in $37.2 \%$ of cases. Compared to Maïga in Togo, Bahri in Algeria, Ouldittou in Morocco an d Fekih Hassen $\mathrm{M}$ et al. who reported a predominance of pneumopathies in subjects aged 55, 53, 50 and 56 years respectively [7] [8] [9] [10]. Lung disease was present in dialysis and non-dialysis patients in $77 \%$ and $23 \%$ of the cases in our series, respectively. Twenty-two out of twenty-seven (22/27) patients on dialysis had alveolar pneumopathy while in the non-dialysis patients pleuropneumonia was observed in six out of eight. A study carried out in Fez [11] in haemodialysis patients noted a frequency of bacterial pneumopathy of $2.49 \%$. The susceptibility of uremic patients to infections is not only explained by increased exposure to the risk of infection, but also by the immune disorders involved in this phenomenon. Uremia is accompanied by abnormalities in innate and adaptive immunity [2] [12].

The sputum cytobacteriological examination (ECBC) was positive in $65.7 \%$ of cases with the presence of leukocytes in $68.6 \%$ of cases. The germs found were: Klebsiella pneumoniae (25.7\% of cases), Escherica coli (11.4\%), Pseudomonas aeruginosa (5.7\%), Staphylococcus aureus (5.7\%), Citrobacter freundi (5.7\%), Enterococus sp. (2.9\%), Enterobacter cloacae (2.9\%), Candida albicans (5.7\%) and 12 sterile cases. Previous antibiotic therapy is found in $34.3 \%$ of cases. This may explain the bacteriological negativity in the 12 patients. In the literature, Fekih Hassen [10] found a germ in 15 cases, including 9 pneumococci, 4 gramnegative bacilli, 2 gram-positive cocci. Bahri in Algeria in 2017 found Klebsiella pneumoniae as the most common germ in $16 \%$ of cases [9]. Contrary to the ECBC results of Fekih Hassen in Tunisia in 2014, which found Streptococcus (43\%), Haemophilus influenzae (18\%), Staphylococcus aureus (13\%), Acinetobacter baumanii (12\%) and Klebsiella pneumoniae (2\%) in the cases [10]. Bahri in Algeria and Zaoui F in Tunisia also reported a predominance of Enterobacteriaceae in $71.3 \%$ and $40.80 \%$ of cases, respectively [8] [13].

There was a urinary co-infection in $40 \%$ of cases. Sprouts isolated in uroculture were Escherica coli (17.1\%), Staphylococcus aureus (5.7\%), Enterococcus sp. (5.7\%), Acinetobacter baumani (2.9\%), Klebsiella pneumoniae (2.9\%), Pseudomonas aeruginosa (2.9\%), Candida albicans (2.9\%). There was no statistically significant relationship between germs found on cytobacteriological examination of sputum and cytobacteriological examination of urine $(\mathrm{p}=0.576)$. An epidemiological study conducted at the Ibn rochd UHC, which included 3933 patients from various hospital departments, observed the prevalence of enterobacteria with an equal frequency of $E$. coli and Klebsiella pneumoniae in patients with both pneumonia and urinary tract infection [14].

All our patients benefited from the exploration of the BAAR in sputum, 4 cases were positive (11.4\%). Patients with both tuberculosis-associated lung disease and tuberculosis accounted for $2.9 \%$. There was an association between the re- 
sults of cytobacteriological examination of sputum and the results of BAAR testing of sputum $(p=0.046)$. In a study of chronic hemodialysis in Mali [15] the incidence of pulmonary tuberculosis was $10.52 \%$. In Morocco [16], the incidence of pulmonary tuberculosis in haemodialysis was $21 \%$.

CRP was positive in all cases, procalcitonin was increased in $65.7 \%$ of patients and hyperleukocytosis was revealed in $60 \%$ of cases. Ouldittou found hyperleukocytosis in $66.4 \%$ of cases [9].

The severity of these chronic kidney diseases results mainly from the abolition of the kidney's ability to perform its excretory functions; metabolic disorders and hydroelectrolytic disturbances may then appear and threaten the renal and vital prognosis [4]. When the diagnosis of bacterial pneumopathy in chronic renal failure was made, the course of action was the initiation of antibiotic therapy sensitive to the isolated germ. The molecules tested and sensitive were Ceftazidim (37.1\%), Ciprofloxacin (22.9\%), Amoxicillin-clavulanic acid (17.1\%), Gentamicin (17.1\%), Meronia (11.4\%), Zaxter (8.6\%) and Erythromicin (2.9\%). Our results are in line with a study carried out in hospitalized patients with chronic renal failure in Morocco on pulmonary infections where the antibiotic prescribed as first-line treatment was a third-generation cephalosporin (50\%), a ciprofloxacin $(31.3 \%)$ and an aminoside was associated in $22.9 \%$ [9]. Contrary to our study, Fakih Hassen in Tunisia in 2014 found in his study that the cephalosporin-quinolone association was the most prescribed [10]. Our patients received antibiotic therapy with an average treatment duration of 10.26 days. Tuberculosis cases were put on anti-tuberculosis drugs adapted to the residual renal function.

The evolution under treatment of pneumopathy was favourable in $74.3 \%$, sputum sterilisation (28.6\%), normalisation of CRP and procalcitonin in $48.8 \%$ and $31.4 \%$ respectively. The control chest X-ray was normal in $37.1 \%$ of cases. On the renal level, the evolution under treatment of pneumopathy was marked by the regression of the stigma of renal damage (creatininemia and blood urea) in $57.1 \%$ of cases and stabilization of renal function in $14.3 \%$. Thus, it can be said that the presence of bacterial pneumopathy is an aggravating factor in these patients with chronic kidney failure. Infectious complications are the second leading cause of death in patients with deficiency [2]. We've recorded 09 deaths in our series.

\section{Conclusion}

Bacterial pneumopathies are common in nephrology. The radio-clinical lesions are varied. The germs involved are numerous. Bacteriological and radiological investigation must be systemic for early and effective management.

\section{Conflicts of Interest}

The authors declare no conflicts of interest regarding the publication of this paper. 


\section{References}

[1] Hulot, J.-S. (2017) Chronic Renal Failure and Chronic Renal Diseases in University College of Teachers of Nephrology. 7th Edition, Edition Ellipses, Paris.

[2] Rieu, Ph. and Touré, F. (2006) Infections and Immunosuppression during Uremia. Jean-Hamburger Nephrology News. Necker Hospital, 229-250.

[3] Hoen, B., Kessler, M., Hestin, D., et al. (1995) Risk Factors for Bacterial Infections in Chronic Haemodialysis Adult Patients: A Multicentre Prospective Survey. Nephrology Dialysis Transplantation, 10, 377-381.

[4] Kessler, M., Hoen, B., Mayeux, D., et al. (1993) Bacteremia in Patients on Chronic Hemodialysis. A Multicenter Prospective Survey. Nephron, 64, 95-100.

https://doi.org/10.1159/000187285

[5] Allon, M., Depner, T.A., Radeva, M., et al. (2003) Impact of Dialysis Dose and Membrane on Infection Related Hospitalization and Death: Result of the HEMO Study. Journal of the American Society of Nephrology, 14, 1863-1870. https://doi.org/10.1097/01.ASN.0000074237.78764.D1

[6] Cohen, G., Haagweber, M. and Horl, W.H. (1997) Immune Dysfunction in Uremia. Kidney International, 52, S79-S82.

[7] Maiga, S., Adambounou, A.-S. and Aziagbe, A.-K. (2017) Particularities of Bacterial Pneumopathies of the Elderly Subject in Hospital in Lomé (Togo). 10 p.

[8] Maroua, B., et al. (2017) Explorations of Bacterial Infections in the Nephrology Department of Tlemcen University Hospital. 68 p.

[9] Ouldittou, I., Serhane, H., Aitbatahar, S., Sajiai, H. and Amro, L. (2017) Service de pneumologie, Pcim laboratory, Ucam, Marrakech, Morocco. Bacteriological Profile of Pneumonia in Diabetic Subjects. 67 p.

[10] Fekih Hassen, M., et al. (2014) Severe Community Lung Diseases in Intensive Care: Clinical, Bacteriological Characteristics and Prognostic Factors: A Tunisian Experience. Revue de Pneumologie Clinique, $71 \mathrm{p}$.

[11] Ikram, D. (2012) Infections in Chronic Haemodialysis Patients (About 81 Cases). Thesis, Fez.

[12] Dammin, G.J., Couch, N.P. and Murray, J.E. (1957) Prolonged Survival of Skin Homografts in Uremic Patients. Annals of the New York Academy of Sciences, 64, 967-976. https://doi.org/10.1111/j.1749-6632.1957.tb52488.x

[13] Fathia, Z., et al. (2017) Description and Place of Bacteriological Techniques in the Management of Pulmonary Infections Tunisia. $121 \mathrm{p}$.

[14] Chemlal, A., Karimi, I., Benabdellah, N., Alaoui, F., Alaoui, S., Haddiya, I., et al. (2015) Urinary Infections in the Patient with Chronic Renal Failure in Nephrology: Bacteriological Profile and Prognosis. Nephrology \& Therapeutic, 11, 399. https://doi.org/10.1016/j.nephro.2015.07.401

[15] Diallo, S., Sissoko, B.F., Toloba, Y., Hassane, F., Mbaye, O., Tamara, A., Keïta, B. and Fongoro, S. (2007) Tuberculosis in Chronic Hemodialysis. Respiratory Disease Review, 24, 108. https://doi.org/10.1016/S0761-8425(07)72721-3

[16] El Amrani, M., Asserraji, M., Bahadi, A., El Kabbaj, D. and Benyahia, M. (2016) Tuberculosis on Hemodialysis. Tropical Medicine and Health, 26, 262-266. https://doi.org/10.1684/mst.2016.0569 